\title{
Civilisations
}

Revue internationale d'anthropologie et de sciences

humaines

$54 \mid 2006$

Expériences de recherche en République

démocratique du Congo

\section{Social Research and Data Collection on Poverty and Underdevelopment in the Congo}

Context, Practice and Problems

\section{Guillaume lyenda}

\section{(2) OpenEdition}

\section{Journals}

Electronic version

URL: http://journals.openedition.org/civilisations/369

DOI: $10.4000 /$ civilisations.369

ISSN: 2032-0442

\section{Publisher}

Institut de sociologie de l'Université Libre de Bruxelles

Printed version

Date of publication: 1 April 2006

Number of pages: 107-115

ISBN: 2-87263-006-6

ISSN: 0009-8140

\section{Electronic reference}

Guillaume Iyenda, « Social Research and Data Collection on Poverty and Underdevelopment in the

Congo », Civilisations [Online], 54 | 2006, Online since 01 April 2009, connection on 19 April 2019. URL : http://journals.openedition.org/civilisations/369 ; DOI : 10.4000/civilisations.369 


\title{
Social Research and Data Collection \\ on Poverty and Underdevelopment in the Congo
}

Context, Practice and Problems

\author{
Guillaume IYENDA
}

Summary: Researching development and collecting empirical data on poverty and underdevelopment are major priorities for social sciences academics and researchers in the Congo. This paper presents different methods of studying urban poverty and underdevelopment in Kinshasa. It focuses on the context in which the qualitative approach and different social science methods are used to allow researchers to gather empirical data on urban poverty, household livelihoods and survival strategies. It goes on to explain how difficult it is to conduct ethnographic research in urban Congo and how researchers should organise their fieldwork. The author uses some examples drawn from his own research carried out in Kinshasa in 2001 and 2004 to help understand the importance of the challenge. The paper demonstrates the complexity of research conditions in Kinshasa and highlights the fact that the concept of carrying out research on urban poverty and underdevelopment in the Congo in general involves in-depth knowledge of the field, people and cultures and the ability to deal with unforeseen difficulties.

Key words: socio-economic surveys, observation, interview, poverty, Kinshasa.

Résumé : Les recherches sur le développement et la récolte de données empiriques sur la pauvreté et le sous-développement sont des priorités pour les chercheurs et les enseignants en sciences sociales au Congo. Cet article présente différentes méthodes utiles pour étudier ces questions à Kinshasa, en mettant en évidence le contexte dans lequel ces méthodes (qualitatives ou autres) sont appliquées pour collecter des données empiriques sur la pauvreté urbaine, l'économie ménagère et les stratégies de survie. Il souligne les difficultés de la recherche ethnographique en milieu urbain congolais et donne des conseils relatifs à l'organisation du "terrain". Les exemples utilisés par l'auteur sont repris de ses recherches menées en 2001 et 2004. En somme, l'article révèle la complexité des conditions de recherche à Kinshasa et démontre combien sont importantes, dans cette entreprise, la capacité du chercheur à s'adapter ainsi que sa connaissance en profondeur de la population et du contexte socio-culturel.

Mots-clés : enquêtes socio-économiques, observation, entretien, pauvreté, Kinshasa. 


\section{Introduction}

The number of studies on poverty and welf are in the Congo are increasing and more young researchers within different social scientific fields are getting involved in researching poverty and underdevelopment in that country in general and in cities in particular. According to Bless and Higson-Smith (1995: 12): "research can be loosely defined as the translation into practice of the relationship between facts and theory... and the endeavour of acquiring knowledge". For Peil et al. (1985: 1), "research is usually designed to handle a problem, something, which needs describing, explaining or improving, or about which more information is needed so that future occurrences can be predicted and policy decided".

All over the country, there are growing research activities about people's day-to-day lives. As Bulmer (1993: 3) argued, "these results are not just fed back to fellow academics, but are used to influence the life chances of millions upon millions of people". In this context, the link between theory and the empirical world is provided, in large part, by research; that is, by examining the empirical world in a systematic way in order to assess the accuracy, truth, adequacy, plausibility of a theory" (Ackroyd and Hughes 1983: 2).

The most significant and noticeable problem that researchers face at the beginning of data collection on urban underdevelopment in the Congo is that many questions arise: how can the results of their studies present an accurate picture of the state of poverty within cities where their research is conducted? How can they produce accurate, meaningful and reliable data which are socially useful? If other researchers came to do the same research after them under the same conditions, would they reach the same conclusions?

The aim of this paper is to present different ways of researching urban poverty and underdevelopment in Kinshasa in particular and in the Congo in general. The focus is on the use of the qualitative approach and presents different methods social scientists use for the collection of data. Moreover, it explains how each method can be applied in the field and what kind of problems a researcher is expected to face in the field. Finally, this paper uses examples drawn from my field research carried out in Kinshasa on urban poverty, households, livelihoods and survival strategies (Iyenda 2001, 2002a, 2002b) to highlight the way different research methods and techniques are used in the field and how researchers can organise their data collection.

\section{Research Practice in Kinshasa}

\section{Literature Review}

Any good research needs a literature review and researchers need to know what is written locally on the subject. This first step of my indirect observation allowed me to obtain materials from various recorded sources of information, and to be informed of 
what has been written locally on urban poverty, households' livelihoods and development strategies by local scholars and others. These sources are: Congo-Afrique, Afrique et Développement, Conjonctures Economiques, Ministry of Planning Monthly's Reports on the evolution of households' budgets and cost of living index; Ministry of Planning's Projects on poverty alleviation, Ministry of Employment's Programmes of unemployment alleviation, Ministry of Social Affairs' Programmes of poverty alleviation, Ministry of Public Administration's Reports on the Situation of income, Ministry of Finances' Evolution of the Congolese currency, The Central Administration of Statistics' Reports, CNONG's (Confédération des ONG du Congo) Reports, FEC's (Fédération des entreprises $d u$ Congo) Reports, the UNDP's Reports, UNICEF's Reports, the ILO's Reports, on the situation of employment in the Congo.

It is to be noted that comparison of reports, bulletins and newsletters on statistics from different sources, even those provided by the so-called serious UN "system", revealed unacceptable inconsistencies and unreliability as each organisation uses different and unspecified definitions of indicators and variables. Moreover, as the statistical sector is poorly financed, data from the government are often weak and lack substance or accuracy, since major activities in the country are unrecorded. Bulmer and Warwick (1993: 4) stressed this concern about inaccuracy of data in developing countries: "if a serious study of the availability of reliable data is undertaken, the situation in many developing countries is likely to be found to be quite alarming. It is not only a question of lack of data; in many situations, the position is more a case of poor quality data than of no data". At the end of my literature review, I designed samples for the areas to be researched.

\section{The Design and the Use of Samples}

A sample is a set of elements, which represents all features of a particular population. During my research, I mainly used probability sampling, which is a statistical procedure for selecting units from a population on some basis of chance. It allows choosing such population units in a way that gives each unit of the group an equal chance of selection. Probability sampling can be a simple random sample, a systematic sample, a stratified or a cluster sample. All are based on the laws of probability.

As it was impossible for me to talk to everyone who could provide information for the study in a city of more than six million inhabitants and to visit all areas covered by the research, I used a sample of the population to be researched. A word of warning needs to be expressed at this stage. Since the late 1970s, sampling according to standard principles has posed serious problems the Congo. In Kinshasa, there are often no readily available sampling frames, no registry of citizens in many municipalities and districts, especially in those built after independence. Furthermore, some streets in those areas are unnamed and many houses are unnumbered. There are no details and information about who lives where, as the last census in the country took place in 1984 and censuses are often manipulated for political reasons.

Establishing a sample was a major problem because the selection of respondents was not easy. As it was difficult to obtain a sampling frame, I used many types of probability sampling. First, I used stratified sampling to select the districts where my research would take place. Stratified sampling allowed me to look at the main characteristics of the districts to be researched. Then, two separate lists of districts were drawn up according to the chosen characteristics. In the end, four of them were selected randomly. These were 
Masina and Ngaba (built mainly after independence) and Matete and Bandalungwa (built before independence).

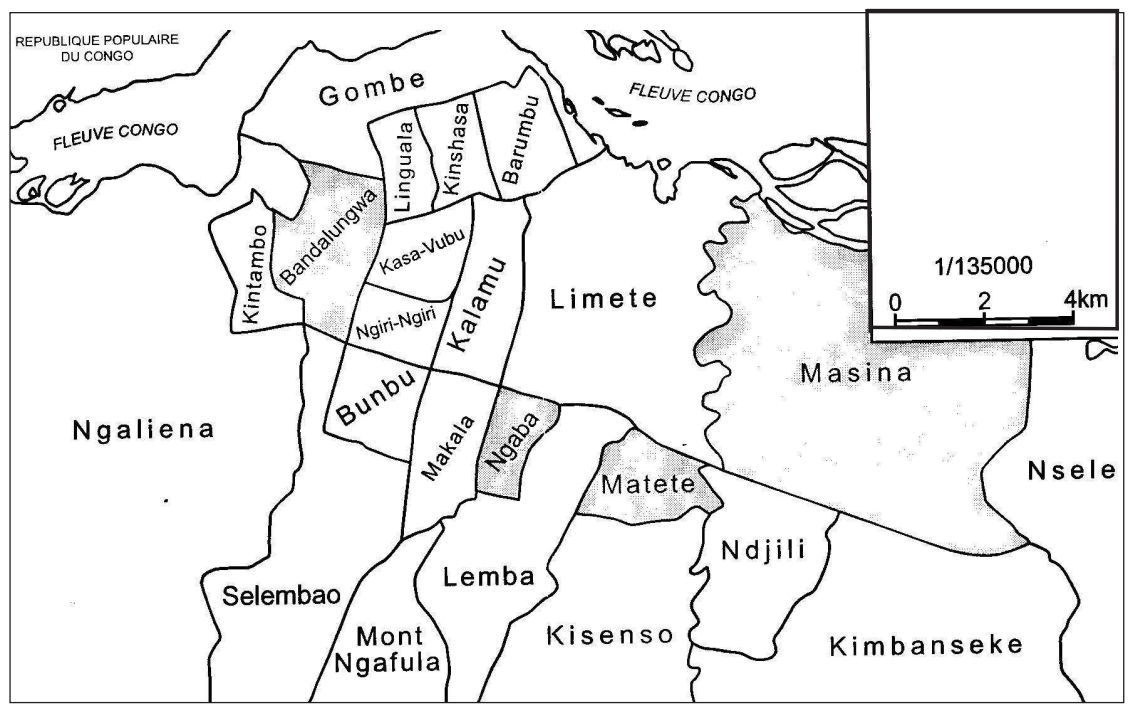

Source: Amended from the Institut géographique de Kinshasa, 2001.

After selecting the districts (highlighted in the map), I used systematic sampling to select the streets and households to be interviewed. I started at a random point and selected every tenth street in each area and the tenth household in each selected street. I used the number ten to facilitate calculations and summing up at the end, as my targeted was to administer 600 interviews, 120 questionnaires and sixteen cases of participant observation. With an accurate picture of my research areas, I started to administer interviews.

\section{Interview}

"Interviews in social research are encounters between a researcher and a respondent in which the latter is asked a series of questions relevant to the subject of the research. The respondent's answers constitute the raw data analysed at a later point in time by the researcher" (Ackroyd and Hughes 1983: 67). That is why Peil suggested that "carrying out a survey requires more preparation than just selecting a sample and working out an interview schedule" (Peil et al. 1985: 130). Interviews are a social situation to which both parties bring expectancies, presuppositions, beliefs and experiences, and without understanding these, any social researcher will be unable to understand the dynamics of interview encounters.

In Kinshasa, I organised interviews in the form of approximately 90 minute conversation with each informant within households and 45 minute conversations outside households (workplaces, streets, markets, shops, ministries). I had to allow people to carry on with 
their work and not distract them for longer. Some weeks, I was obliged to work ten hours per day and others, seven days a week to meet my schedule.

Firstly, I administered 320 interviews within 320 households for 60 days (80 interviews per district and 15 days per district). In addition to 320 household interviews, sixteen other separate interviews were administered within the sixteen selected households where participant observation took place. Secondly, 65 interviews were administered to selfemployed (joiners, mechanics, builders, plumbers, electricians, carpenters, taxi and bus drivers, and cobblers) and this exercise took eight days. I also interviewed 65 informal sector operators (shopkeepers, street vendors, street food makers, craftspeople, tailors and hairdressers) for another eight days. I then interviewed 70 civil servants and private sector workers for ten days. Finally, I administered 64 interviews with agents of the UN (ILO, UNDP, and UNICEF), agents of some international NGOs (CARITAS, Médecins Sans Frontières, Oxfam) and local NGOs. Again, this exercise took eight days. At the end, 264 interviews were conducted outside households. In total, 600 interviews were administered during the fieldwork.

I used semi-structured interviews, which have the advantage of combining standardised and non-standardised question formats. The key advantage of the semi-structured interview is that it permits the "gaining of extensive information, verified by extended discussion and probing in problem areas" (Guy et al. 1997: 245). My questions were drawn up prior to the beginning of the research. While researching, I had to ask specific questions and, at the same time, I was free to probe beyond my list of questions as necessary. I used standardised questions to get some kinds of information, such as the marital status, gender, age, and level of education of the interviewee. Within households, interviewees were asked a series of questions within six different clusters: their accommodation, their food and household goods, their education, their health, their transport and social expenditures, their livelihoods and their survival strategies. Within the public administration, ministries, the UN system and the civil society, a seventh cluster was added on development strategies and policies for Congolese cities.

To a question about why did he become a builder, Manwana in Ngaba replied:

I decided to become a builder because my profession has a secure future in this growing city. The urban Congolese population is growing faster and people will always build houses. Therefore, a builder in Kinshasa will never suffer from hunger or lack a job. What I get from my job allows me and my family to live and that is it.

When asked how informal relationships, informal social networks and informal trust between people allowed them to get contracts, sell their goods, succeed in business and fight against poverty, Mr Bwang, a carpenter in Bandalungwa replied:

It has become impossible for us to continue working without using our informal networks and relationships. Since 1996, orders have seriously decreased because of the crisis. Nowadays, people do not have enough money to purchase new furniture as they used to do a decade ago and many households do not replace their furniture regularly as they did in the 1980s. Therefore, our relatives, neighbours, and friends bring customers here. They bring their colleagues from work, their neighbours, their friends and in-laws, members of their political parties and members of their churches. Actually, no one in our sector can sell goods without an important network of relationships throughout the city.

The end of interviews was followed by the administration of questionnaires. 


\section{The Design and the Administration of a Questionnaire}

The administration of questionnaires took place in streets and households different to that where interviews and participant observation were organised. Knowledge and understanding of the population to be questioned, their sociological and intellectual structures have all to be taken into account while drafting a questionnaire if a good result is to be obtained.

I took great care over the wording of questions before the beginning of my research. Each question had to be precise and free from any confusion or ambiguity. It has to express only a single and clear idea. I made a particular effort to produce a short, feasible and understandable questionnaire. The order of questions was another important issue, as easy and uncontroversial questions were asked at the beginning of the questionnaire to facilitate answers. Questions on personal and intimate matters like income came later, because I avoided raising people's suspicions.

In Kinshasa, questionnaires were given to 120 selected people within the chosen districts. Selection of respondents depended on their ability to read and write a single sentence in French (which is the official and administrative language in the Congo) without any assistance. The fear of any bias or any exclusion was eliminated as interviews and other methods covered literate and illiterate people. With a starting point different to that for the interview, every tenth street in each area was selected and each tenth household in the street was selected for answering the questions.

The use of structured self-completed questionnaires is easy in a country with an efficient postal service. In the Congo, the postal service has essentially collapsed. Often, the post never arrives and many people do not have postal addresses. I had to dispatch and hand out individually all questionnaires and then collect the responses. This allowed me to encourage respondents to participate in the research. As people are struggling to find survival means for their households and seem busy every day, I returned to collect answers two months later. I revisited some households two to three times to collect the questionnaires and for those who lost the first copy and who wanted to participate to the research, I gave them another copy.

At the end of the exercise, 109 out of 120 questionnaires were collected, that is to say nearly $91 \%$, which represents a remarkably high response rate. Although it is always difficult to rely on self-completed questions, more than $95 \%$ of questions were answered. As the questionnaire was anonymous, many people responded with honesty and provided more details than expected regarding their livelihoods, their incomes, the quality of their accommodations and foods, their access to the health system and its quality, their children's quality of education, their transport and social expenses and their survival strategies.

\section{Participant Observation}

Participant observation has been used from the early stage of social sciences, especially in cultural anthropology. As a research method for social scientists, participant observation involves more than just looking at what is going on. Because our subjects can talk and therefore explain their behaviour, observation includes listening and asking questions, and often participating in activities of the group to get the first hand experience of what daily life involves (Peil et al. 1985: 158). Ackroyd and Hughes (1983: 98) argued that "participant observation, as its name implies, requires the investigator to involve himself or herself in the lives of those being studied, and so involves a number of activities including looking, listening, enquiring, and recording". 
As said earlier, participant observation took place within sixteen households (four households per district) in streets and households different to those were interviews and questionnaires were organised. I spent three days in each selected household. Some households were headed by single mothers, some by unemployed people, some by wage earners and others by informal sector workers. Its aim was to allow me to obtain "an insider's" view of the reality of my study and to examine how people lived in households and in communities, what happened each day of their lives, how they organised their lives and how they struggled against poverty.

I was constantly obliged to discuss my project at all stages with the heads of households and their wives or husbands. I had to uphold the trust and friendship that everyone placed in me and in my study. As the Congo is currently immersed in severe political turmoil, I had to avoid being seen as a spy. I told my host families about the research objectives, the fields to be researched and the use of the research results.

I participated openly in daily lives of my respondents. I had to listen, watch, talk, work with them, do what they were doing, eat what they were eating, be sociable, carry, sell what their were selling, do the shopping, grow vegetable in fields, polish shoes, etc. This method allowed me to cook food, to wash clothes and children, to clean houses and dishes. While living with my hosts, I was able to evaluate the quality of their houses, its furniture, its apparatus; and while eating with them, I could evaluated the quality of their food, the number of meals they consumed per day, the quality of clothes they used, and the quality of education and health services provided to their members. Because I was involved in the daily management of their households, I was able to obtain an accurate idea of their daily expenditure.

However, I had to leave my host family every day after $11 \mathrm{pm}$ and go back to sleep at home because many selected households only had a maximum of two rooms for eight to ten people of all age and both genders. Therefore, I did not have a small space to sleep. I had to go and sleep at home and come back early in the morning. This did not have any implications for the research process because I left my selected household when people were sleeping and I arrived the next morning before they awoke.

Indeed, as I had to live for a period of time within some households, I faced the critical issue of avoiding the invasion of privacy of my hosts. "As a general principle, the right to knowledge must be balanced by the rights to personal and community integrity and privacy" (Peil et al. 1985: 18). Therefore, I needed to be neutral while I was observing what was going on and doing what people in households under study were doing to avoid becoming the centre of attraction.

My daily contacts with individuals in their households were compulsory and during that time, I needed to do some formal interviews. Ultimately, participant observation gave me the reliability of data collected by interviews or questionnaires and allowed me, as Ackroyd and Hughes (1983: 113) wrote, "to study a group in its natural setting and, moreover, to study the group for far longer and in more depth than is possible with the survey or any other research strategy".

\section{Data Analysis}

Although the aims of the study and the nature of the research dictate methods to be used, the induction process and the qualitative approach were the most used for this empirical and ethnographic research. The analysis of data of a study of this scale needed careful consideration and the use of different methods. This multi-choice of research 
methods follows Bennett and Thaiss (quoted in Bulmer and Warwick 1993: 275), who remarked that "the human reality must be apprehended by a variety of viewpoints, not by one alone, because this very reality is always in part in construction, always in part an image, and only by encouraging difference in perspective and approach can one obtain the needed richness of imagery, and consequently, theory". Ultimately, cluster analysis, event analysis, factor analysis and multidimensional analysis allowed me to analyse my data, to reach my goals and to better understand the meanings of my study. The gathering of facts was geared towards the generalisation of findings, which allowed the deriving of theoretical conclusions at the end of the study.

\section{Problems and Difficulties in the Field}

The application of research methods and data collection in Africa in general and in the Congo in particular is very different to what is being done in the West. In Kinshasa, few people are ready to give their views publicly on what is going on in their lives. People are afraid of the authorities. The regime that rules the country, wrongfully and arbitrarily arrests, tortures and imprisons people. The civil war in the country did not help the process of data collection either. In all selected districts, people were reluctant to talk to someone they did not know. Some of them thought I was a spy or I needed to get information from them and report them later to the authorities. In Ngaba in particular, people's low level of education made it difficult for them to express their own opinions on what should be done to improve their living conditions.

I faced many obstacles in Masina to interview women or to work with women in households in the absence of their husbands, as people have become suspicious and do not trust strangers. The wide difference between communities in terms of their social, economic and cultural background, their demographic size, and their level of poverty made my research more difficult than anticipated. While researching, I had to postpone my interviews because people in the selected household did not eat for a day, sometimes because I did not get a taxi or the lack of petrol around the city did not allow private taxis to operate.

\section{Conclusion}

Throughout this paper, I have presented different tools, which can allow researchers to collect reliable information on the situation of poverty faced by urban communities and many households in Kinshasa. Although interviewing was a very frustrating and harrowing experience, it was the main and the best method of data collection used during that research. During that time, I realised that to carry out a successful field research, a researcher needs to have a good knowledge of the city, people, culture, customs and the official language used by local people. These enable him/her to assess the quality of responses. People's attitude, words, social position, facial expression and gestures can allow him/her to decode their feelings. As Taylor and Bogdan (1998: 7) suggested, "qualitative methodology refers to research that produces descriptive data-people's own written or spoken words and observable behaviour".

Since scientific and academic research should be characterised by honesty, researchers have to tell interviewees who they are, why they are there and how the result of this study is to be used. They have to give them guarantees about confidentiality. They have to give all respondents the chance to talk anonymously and let everyone feel assured that 
their responses will not be disclosed to the authorities. Although researches varies with circumstances, people and areas, a researcher has to communicate trust and reassurance to allow everybody to maintain interest in the research.

\section{References}

Ackroyd, S. and J. A. Hughes, 1983. Data Collection in Context. London and New York: Longman.

Bless, C. and C. Higson-Smith, 1995. Fundamentals of social Research Methods: An African Perspective. Cape Town: Juta.

Bulmer, M. and D. P. Warwick (eds), 1993. Social Research in Developing Countries. Surveys and Censuses in the Third World. London: UCL Press.

Guy, R. F. et al., 1987. Social Research Methods: Puzzles and Solutions. Boston: Allyn and Bacon.

IYENDA, G.

2001. "Street Foods and Income Generation for Poor Households in Kinshasa", Environment and Urbanisation, 13, October, pp. 233-241.

2002a. "Pauvreté Urbaine et Secteur Informel à Kinshasa", Développement et Coopération, 5 (SeptemberOctober), pp. 18-21.

2002b. Urban Poverty and Households'Livelihoods: Sociological Study of Strategies for Development of Congolese Cities. PhD Dissertation, Royal Holloway, University of London, Unpublished.

Peil, M. et al., 1985. Social Sciences Research Methods. An African Handbook. London and Sydney: Hodder and Stoughton.

TAYlor, S. T. and R. Bogdan, 1998. Introduction to Qualitative Research Methods. A Guide and Resource. New York: John Wiley \& Sons. 
